\title{
PET-based myocardial efficiency: Powerful yet under-utilized-now simpler than ever
}

\author{
Frank M. Bengel, $\mathrm{MD}^{\mathrm{a}}$ \\ a Department of Nuclear Medicine, Hannover Medical School, Hannover, Germany
}

Received Jul 31, 2018; accepted Jul 31, 2018

doi: $10.1007 / \mathrm{s} 12350-018-1400-y$

\section{See related articles, pp. 1929-1936 and pp. 1937-1244}

Efficiency is defined as the ratio between energy output and energy input of a system. For the myocardium, this can be described by the amount of external work (or pressure) that is created, relative to the amount of energy (or oxygen) that is consumed. The failing heart is inherently ineffective: It cannot create sufficient external work without compensatory support mechanisms such as increased peripheral vasoconstriction. As a consequence, internal effort and oxygen consumption increase and an energetically unfavorable, inefficient state emerges. ${ }^{1}$ Countering this harmful situation of impaired myocardial efficiency is a primary goal of many heart failure therapies. Accordingly, diagnostic techniques enabling the interrogation of myocardial efficiency may be of considerable value in heart failure therapy and drug development. ${ }^{2}$

Traditionally, myocardial efficiency has been defined and analyzed by directly measured pressurevolume loops during the cardiac cycle, but this invasive technique remains experimental and is difficult to apply serially. In an effort to establish non-invasive estimates of myocardial efficiency, C-11 acetate PET has emerged as a key technique. Following intravenous injection, $\mathrm{C}$ 11 acetate is taken up by the myocardium in proportion to myocardial blood flow, where it is transformed to C11 acetyl-CoA. Acetyl-CoA enters the tricarboxylic acid (TCA) cycle where it is metabolized to carbon dioxide which is cleared from the myocardium. The wash-out

Reprint requests: Frank M. Bengel, MD, Department of Nuclear Medicine, Hannover Medical School, Carl-Neuberg-Str. 1, 30625,

Hannover, Germany; bengel.frank@mh-hannover.de

J Nucl Cardiol 2018;25:1945-7.

$1071-3581 / \$ 34.00$

Copyright (C) 2018 American Society of Nuclear Cardiology. rate of $\mathrm{C}-11$ from the myocardium accordingly reflects TCA cycle flux and thus oxidative metabolism. ${ }^{3}$ In order to determine efficiency, measures of oxygen consumption by $\mathrm{C}-11$ acetate PET need to be combined with measures of cardiac output and arterial pressure to define work. The non-invasive work-metabolic index has been established as a non-invasive efficiency marker. ${ }^{4}$

Following its methodological development and introduction, it was shown that the work-metabolic index is indeed impaired in heart failure, where oxygen consumption for a given amount of work is elevated. ${ }^{4-6}$ Importantly, it was shown in a series of subsequent studies that this powerful PET-derived parameter does not only provide mechanistic insights into cardiac mechanics and metabolism in health and disease. ${ }^{7-11}$ It has also been used to support the beneficial effects of various heart failure therapies on myocardial efficiency, including various drug therapies ${ }^{4,12,13}$ but also devices ${ }^{14}$ and other interventions. ${ }^{15,16}$ Successful therapies increase efficiency either by increasing the amount of generated external work without a concomitant increase of oxygen consumption, or by reducing the amount of oxygen needed for maintaining the same level of external work. Very small sample sizes of $<20$ patients are needed to define the benefit of a therapy, ${ }^{13}$ supporting the usefulness and power of C-11 acetate-based efficiency measurement as a surrogate marker of success. $^{17}$

Given the increasing prevalence of heart failure and the increasing spectrum of novel therapeutic options, ${ }^{18}$ PET-defined efficiency thus has a strong potential as a serially applied imaging biomarker in heart failure drug development. ${ }^{2}$ Yet, few studies have used this marker on a multi-center trial level so far. One limiting factor for a broader application is the short half-life of C-11 (20 minutes), which makes an on-site cyclotron for tracer production a necessity. But the success and increasing application of PET in oncology result in an increasing availability of cyclotrons for tracer 
production, helping to overcome this issue. $\mathrm{C}-11$ acetate studies are rapidly completed in $30 \mathrm{~min}$ or less, so that scanner time availability will not be critical.

A second limiting factor for C-11 acetate-based efficiency measurements has been the need for additional measurements of cardiac work by a functional imaging test. Cine magnetic resonance imaging, radionuclide angiography, or echocardiography can be done sequentially after of before PET, but this bears the limitation that both studies are not acquired simultaneously, may not reflect identical conditions and may not be used to determine rapid drug effects without repeated exposures. For simultaneous measurements, echo can be obtained during PET or hybrid PET-MR may be employed, but both approaches are technically challenging for different reasons.

A solution to this limitation is provided in this issue of the Journal of Nuclear Cardiology, by researchers from the Universities of Aarhus/Denmark and Uppsala/ Sweden. In a series of two manuscripts, Harms, Hansson, Sorensen, and colleagues provide key information on a novel approach to determine efficiency from a single dynamic C-11 acetate PET scan, without the need for concomitant echo, MRI or other functional testing. ${ }^{19,20}$ Their approach is based on using the early first pass phase of dynamic PET for determining forward cardiac output and on using the peak uptake phase for determining left ventricular mass. Taken together with systemic blood pressure and wash-out rate of C-11 acetate as a measure of oxygen consumption, this yields all parameters necessary to determine myocardial efficiency. In the first of their two papers, ${ }^{20}$ the authors introduce their new approach in healthy controls, validate it versus the best possible prior technique (a combination of MRI and PET), and show that their marker is sensitive to define abnormalities in two groups of patients with valvular disease. Of note, the new software used for analysis is freely available for noncommercial use. In the second of their two papers, ${ }^{19}$ the authors provide valuable information on the test-retest repeatability of their new approach when compared to other combinations of C-11 acetate PET and functional testing for efficiency measurements. This work supports the high repeatability and confirms that trials will be possible with very low sample sizes of 15 or less to determine effects of a therapeutic intervention by serial measurements (the exact calculated sample sizes are highlighted in the manuscript for each given setting).

In summary, these two important manuscripts provide key methodological advances and repeatability data for a broader application of non-invasive efficiency measurements in heart failure drug development in the future. It will be up to the field of nuclear cardiology to promote this simplified, yet very powerful technique for a broader application in clinical trials. A broader application based on the proposed simplified, standardized analysis may lead to further evidence on a potential prognostic value of efficiency in heart failure, and towards a potential future of individually tailored, efficiency-guided medical heart failure therapy in the clinics. The tools are now here to work towards this vision, which would further augment the nuclear cardiology toolbox in cardiology.

\section{Disclosure}

Dr. Bengel receives grant support and speaker honoraria from GE Healthcare and Siemens AG. This support is not related to the topic of this manuscript. There are no other conflicts of interest.

\section{References}

1. Opie LH. The heart: Physiology, from cell to circulation. 3rd ed. Philadelphia: Lippincott, Williams \& Wilkins; 1998. p. 368-9.

2. Knaapen P, Germans T, Knuuti J, Paulus WJ, Dijkmans PA, Allaart CP, Lammertsma AA, Visser FC. Myocardial energetics and efficiency: current status of the noninvasive approach. Circulation 2007; 115:918-27.

3. Schwaiger M, Beanlands R, vom Dahl J. Metabolic tissue characterization in the failing heart by positron emission tomography. Eur Heart J 1994;15:14-9.

4. Beanlands RS, Bach DS, Raylman R, Armstrong WF, Wilson V, Montieth M, Moore CK, Bates E, Schwaiger M. Acute effects of dobutamine on myocardial oxygen consumption and cardiac efficiency measured using carbon-11 acetate kinetics in patients with dilated cardiomyopathy. J Am Coll Cardiol 1993;22:1389-98.

5. Bengel FM, Permanetter B, Ungerer M, Nekolla S, Schwaiger M. Non-invasive estimation of myocardial efficiency using positron emission tomography and carbon-11 acetate-comparison between the normal and failing human heart. Eur J Nucl Med 2000;27:319-26.

6. Laine H, Katoh C, Luotolahti M, Yki-Jarvinen H, Kantola I, Jula A, Takala TO, Ruotsalainen U, Iida H, Haaparanta M, Nuutila P, Knuuti J. Myocardial oxygen consumption is unchanged but efficiency is reduced in patients with essential hypertension and left ventricular hypertrophy. Circulation 1999;100:2425-30.

7. Bengel FM, Nekolla SG, Ibrahim T, Weniger C, Ziegler SI, Schwaiger M. Effect of thyroid hormones on cardiac function, geometry, and oxidative metabolism assessed noninvasively by positron emission tomography and magnetic resonance imaging. $\mathrm{J}$ Clin Endocrinol Metab 2000;85:1822-7.

8. Bengel FM, Permanetter B, Ungerer M, Nekolla SG, Schwaiger M. Alterations of the sympathetic nervous system and metabolic performance of the cardiomyopathic heart. Eur J Nucl Med Mol Imaging 2002;29:198-202.

9. Bengel FM, Ueberfuhr P, Schiepel N, Nekolla SG, Reichart B, Schwaiger M. Myocardial efficiency and sympathetic reinnervation after orthotopic heart transplantation: a noninvasive study with positron emission tomography. Circulation 2001;103:1881-6.

10. Peterson LR, Herrero P, Schechtman KB, Racette SB, Waggoner AD, Kisrieva-Ware Z, Dence C, Klein S, Marsala J, Meyer T, Gropler RJ. Effect of obesity and insulin resistance on myocardial 
substrate metabolism and efficiency in young women. Circulation 2004;109:2191-6.

11. Tuunanen H, Engblom E, Naum A, Nagren K, Hesse B, Airaksinen KE, Nuutila P, Iozzo P, Ukkonen H, Opie LH, Knuuti J. Free fatty acid depletion acutely decreases cardiac work and efficiency in cardiomyopathic heart failure. Circulation 2006;114:2130-7.

12. Beanlands RS, Armstrong WF, Hicks RJ, Nicklas J, Moore C, Hutchins GD, Wolpers HG, Schwaiger M. The effects of afterload reduction on myocardial carbon 11-labeled acetate kinetics and noninvasively estimated mechanical efficiency in patients with dilated cardiomyopathy. J Nucl Cardiol 1994;1:3-16.

13. Beanlands RS, Nahmias C, Gordon E, Coates G, deKemp R, Firnau G, Fallen E. The effects of beta(1)-blockade on oxidative metabolism and the metabolic cost of ventricular work in patients with left ventricular dysfunction: A double-blind, placebo-controlled, positron-emission tomography study. Circulation 2000;102:2070-5.

14. Ukkonen H, Beanlands RS, Burwash IG, de Kemp RA, Nahmias C, Fallen E, Hill MR, Tang AS. Effect of cardiac resynchronization on myocardial efficiency and regional oxidative metabolism. Circulation 2003;107:28-31.

15. Hall AB, Ziadi MC, Leech JA, Chen SY, Burwash IG, Renaud J, deKemp RA, Haddad H, Mielniczuk LM, Yoshinaga K, Guo A, Chen L, Walter O, Garrard L, DaSilva JN, Floras JS, Beanlands RS. Effects of short-term continuous positive airway pressure on myocardial sympathetic nerve function and energetics in patients with heart failure and obstructive sleep apnea: a randomized study. Circulation 2014;130:892-901.

16. Stolen KQ, Kemppainen J, Ukkonen H, Kalliokoski KK, Luotolahti M, Lehikoinen P, Hamalainen H, Salo T, Airaksinen KE, Nuutila $P$, Knuuti $J$. Exercise training improves biventricular oxidative metabolism and left ventricular efficiency in patients with dilated cardiomyopathy. J Am Coll Cardiol 2003;41:460-7.

17. Wu KY, Dinculescu V, Renaud JM, Chen SY, Burwash IG, Mielniczuk LM. Beanlands RSB and deKemp RA. Repeatable and reproducible measurements of myocardial oxidative metabolism, blood flow and external efficiency using (11)C-acetate PET. J Nucl Cardiol 2018. https://doi.org/10.1007/s12350-018-1206-y.

18. Bengel FM, George RT, Schuleri KH, Lardo AC, Wollert KC. Image-guided therapies for myocardial repair: concepts and practical implementation. Eur Heart $\mathrm{J}$ Cardiovasc Imaging 2013;14:741-51.

19. Hansson NH, Harms HJ, Kim WY, Nielsen R, Tolbod LP, Frokiaer J, Bouchelouche K, Poulsen SH, Wiggers H, Parner ET, Sorensen J. Test-retest repeatability of myocardial oxidative metabolism and efficiency using standalone dynamic (11)C-acetate PET and multimodality approaches in healthy controls. J Nucl Cardiol 2018. https://doi.org/10.1007/s12350-018-1302-z.

20. Harms HJ, Hansson NHS, Kero T, Baron T, Tolbod LP, Kim WY, Frokiaer J, Flachskampf FA, Wiggers H, Sorensen J. Automatic calculation of myocardial external efficiency using a single (11)Cacetate PET scan. J Nucl Cardiol 2018. https://doi.org/10.1007/ s12350-018-1338-0. 